\title{
What do we read to our children? Messages concerning ethnic diversity in popular children's books in the Netherlands
}

\author{
Ymke de Bruijn ${ }^{1}$ (D) . Rosanneke A. G. Emmen ${ }^{1,2}$. Judi Mesman ${ }^{1,2}$
}

Received: 19 January 2021 / Accepted: 22 July 2021 / Published online: 20 August 2021

(c) The Author(s) 2021

\begin{abstract}
Children's books can create opportunities for children to see themselves as well as others in different settings and stories, but cultural details and specificity within these stories can play an important role in the messages that children take away. Therefore, the present study aims to provide insight in the messages concerning ethnic diversity and various cultures in a subset of popular books that Dutch young children are likely to be exposed to. Books aimed at young children that were sold or borrowed most often or were awarded between 2009 and 2018 in the Netherlands are examined through the combined lens of critical race theory and critical multicultural analysis. Specifically, books including a protagonist or secondary character of color were selected. The study provides insight in the degree of cultural specificity and cultural authenticity, as well as prevailing power relations between characters and ideologies that are portrayed within the books. Results indicate that while cultural stereotypes and ideologies including White supremacy and eurocentrism are found only in a few books, cultural details are generally lacking and colorblindness is common in books aimed at young children. The study therefore underlines the particular need for books that are culturally specific and include authentic cultural details, to improve the reflection of various cultures and experiences of characters of color.
\end{abstract}

Keywords Children's literature $\cdot$ Ethnic diversity $\cdot$ Critical race theory $\cdot$ Critical multicultural analysis

Ymke de Bruijn

y.de.bruijn@luc.leidenuniv.nl

1 Leiden University College, Faculty of Governance and Global Affairs, Leiden University, The Hague, The Netherlands

2 Institute of Education and Child Studies, Faculty of Social and Behavioural Sciences, Leiden University, Leiden, The Netherlands 
Picturebooks are a form of children's literature that is characterized by the combination of visual and textual information (Nikolajeva and Scott 2013). These and other books aimed at young children are often read together with an adult, and can help children learn about themselves as well as about others (Bishop 1990). Scholars have advocated for the representation of ethnically diverse characters, so that all children can identify with characters and learn about other cultures. Various studies have established that characters of color in children's books are rare or underrepresented (e.g., de Bruijn et al. 2021; Koss 2015; Koss et al. 2017). In addition, mere representation is not enough for readers to identify with characters, or for books to teach children about various cultures: it is also important how these characters of color and their environments are portrayed, and what values and messages are conveyed within the stories. Two frameworks can combinedly be applied to examine these issues: critical race theory (CRT), which focuses on race and the role of racism, and critical multicultural analysis (CMA), which more specifically focuses on power relations (Solórzano 1997; Botelho and Rudman 2009). The present study will examine popular books for young children (i.e., 6 years or younger) including protagonists or secondary characters of color in the Netherlands through the combined lens of CRT and CMA. Results from the present study will provide insight in the content of stories to which Dutch children are exposed: even if characters of color are included, how are they portrayed and what messages about these characters and their relations with others are conveyed?

\section{The purpose of children's books}

Bishop (1990) argued that books have to act as mirrors, as windows, and as glass sliding doors. The description of books as mirrors implies that ethnically diverse characters are needed, so that all children can identify with characters, which can impact their self-development (Roethler 1998) and potentially provide examples to learn from. In addition, being able to identify with characters might motivate children to read, which can positively impact their reading literacy (Becker et al. 2010). The description of books as windows, on the other hand, implies that children can learn about other cultures and cultural values. Windows can at the same time function as glass sliding doors, so that readers can pass through them and engage in the world created in the book (Bishop 1990), but whether this potential is reached seems dependent on factors such as readers' emotional connection, response, and reflection (Johnson et al. 2018). Books can therefore serve different functions for different readers. Indeed, previous studies have demonstrated that reading multicultural literature can have an impact on children's interethnic attitudes (So 2016), as well as on the cultural awareness and perceived ability to be culturally responsive of (prospective) professionals in education working with multicultural literature (Frye et al. 2010; Iwai 2013). Furthermore, books featuring characters with various ethnic backgrounds have the potential to establish extended contact effects, meaning that examples of characters with an ethnic appearance similar to that of the reader being friends with characters with a different ethnic appearance can positively influence readers' interethnic attitudes 
(Wright et al. 1997). Previous studies have demonstrated this positive effect among children between ages 5 and 11 years (e.g., Cameron et al. 2006, 2007).

\section{Focus on ethnicity and race}

A review of work on the development of racial categorization describes that children can already perceptually differentiate between faces from people with different racial backgrounds in infancy, and are able to categorize based on race by 3- to 4-years of age (Pauker et al. 2017). Thus, from very early on racial differences are recognized by children. A focus on ethnicity and race when analyzing literature for these young age groups seems essential to examine whether children's literature makes use of its full potential to work as mirrors and windows (or even glass sliding doors), as well as to provide examples of interethnic contact and friendships. Race and ethnicity are highly debated socially constructed terms, sometimes used to refer to 'groups' of people based on either features that are argued to be biologically based (race), or on sociological or anthropological features such as shared customs (ethnicity, Quintana 1998). Although from this perspective these terms are distinct, it is argued that children's understanding of ethnicity is initially mostly based on physical, racial characteristics (Quintana 1994). Other scholars, in addition, have described that race is an inappropriate term to describe biological variation in humans (Keita et al. 2004), and argue that ethnic groups are based on common culture, origins and history (Brown and Langer 2010), and are associated with race (Berreman 1972). In this paper, we follow this latter perspective and thus 'ethnicity' is predominantly used when examining physical characteristics and cultural details of characters. However, the term 'race' is used when discussing previous literature that refers to race.

CRT encompasses a framework with a specific focus on race and racism (Solórzano 1997). Although CRT stems from legal studies, it has been applied to numerous fields in the social sciences, including education and psychology (Crenshaw 2010). CRT in education research is guided by five tenets: (1) centrality and intersectionality of race and racism, (2) challenge to dominant ideology, (3) centrality of experiential knowledge, (4) an interdisciplinary perspective, and (5) commitment to social justice (Solórzano 1998). In a research note, Huber et al. (2018) propose that these tenets can also be applied to the analysis of children's literature, exemplified with the following questions:

What identities or characteristics are assigned by race and/or its intersections with class and gender? How are the experiences of People of Color represented, or not? In what ways does the story become raced, or not? Is there a context to situate race and/or its intersections (e.g., historical, political, social)? How/do dominant ideologies operate (e.g., white supremacy, patriarchy, cultural deficits)? In what other ways does power operate (e.g., vantage point, resolution, and/or assumptions of the story)? (Huber et al. 2018, p. 16) 
Through these questions, the authors state that they center race (tenet 1), while focusing on dominant ideologies (tenet 2), and recognizing the importance of experiences of people of color (tenet 3). In addition, Huber et al. (2018) state that questions concerning the interplay of race and power, and the contexts ask for an interdisciplinary approach (tenet 4), and together challenge the interposal of oppression in children's literature (tenet 5).

Previous studies have applied CRT to the analysis of children's literature. One branch of research has focused on the representation of authors, illustrators and characters of color in children's literature, and demonstrated that their representation was rare (e.g., Hughes-Hassell et al. 2009; McNair 2008a). This suggest that the range of available children's books do not use their full potential of providing all children examples and characters to identify with and teaching them about various cultures and worldviews, nor of providing examples of intergroup friendships. In addition, CRT has been used to assess the content of and messages conveyed in multicultural books (e.g., Brooks 2009; McNair 2008b), using concepts such as permanence of race, interest convergence (i.e., equality and equity for people of color will only be pursued when it is in line with the interest and ideologies of White people; Milner 2008), whiteness as property (i.e., along lines of property rights, being born White carries privileges; Hughes-Hassell et al. 2009), colorblindness (i.e., the dismissal and neglect of the cultural, racial or ethnic experience of people of color; Winograd 2011), and counter-storytelling (for an overview see Huber et al. 2018).

Another framework applicable to analyzing how people of color and their environments are portrayed and what values and messages are conveyed, is CMA: a framework developed to encourage teachers and educators to critically analyze and read children's literature, and help children acquire these same skills (Botelho \& Rudman 2009). CMA necessitates a focus on power relations of class, race and gender, and a connection to issues of social change and justice (Botelho \& Rudman 2009). The authors refer to example critical questions to be used:

What (or whose) view of the world, or kinds of behaviors are presented as normal by the text? Why is the text written that way? How else could it have been written? What assumptions does the text make about age, gender, class and culture? Who is silenced/heard here? Whose interests might be best served by the text? What ideological positions can you identify? What are the possible readings of this situation/event/character? How did you get to that reading? What moral or political position does a reading support? How do particular cultural and social contexts make particular readings available? How might it be challenged? (Wooldridge, as cited in Botelho \& Rudman 2009, p. 4)

The authors highlight that the point of view, social processes among characters, story ending, and imbedded assumptions need to be considered, and that both linguistic and visual information in children's literature are important (Botelho \& Rudman 2009).

Previous studies have used CMA to analyze children's literature, examining power in various ways (e.g., Johnson \& Gasiewicz 2016; Kelley 2008; Malcolm \& Lowery 2011; Richards 2013). Richards (2013) for example focused on power in terms of ideologies that are represented in Jamaican children's literature. Similarly, 
Malcolm and Lowery (2011) examined power by studying representations of the Caribbean in children's literature while identifying thematic trends and assessing authenticity. Johnson and Gasiewicz (2016) examined the characterization of immigrant characters and cultures, but in addition investigated power relations among characters. Kelley (2008) looked at power in relation to characters too, but focused on character's actions and responses to power, and whether and how characters benefited from power.

These previous analyses exemplify that CRT and CMA show some overlap in focus, can simultaneously be applied to both the character- and story-level, and can be used to analyze race as well as ethnicity. Whereas CRT provides more detailed guidelines and exemplary questions on how to examine race and racism, CMA provides a more detailed and specific focus on power relations. As both theoretical frameworks have been applied to children's literature in various ways, combining these methods allows for the present research to be inspired by a wide range of exemplary analyses of race and/or ethnicity and related power issues within children's literature.

\section{Analyzing characters}

In accordance with CMA, important issues when examining the quality of the representation of characters are whether the character has an active rather than a passive or subservient role, and whether the character is described in a positive manner (e.g., Al-Hazza and Bucher 2008; Cole and Valentine 2000). Further, in light of the extended contact theory (Wright et al. 1997) characters' relationships with others across ethnic boundaries should be examined, and the representation needs to be culturally authentic. Although this concept is complex and somewhat controversial (Fox and Short 2003), it generally refers to the absence of stereotypes and the depiction of accurate cultural values and details (Yoo-Lee et al. 2014). Imaginably, reading books in which only very stereotypical characters of color are presented might impact children's interethnic attitudes in a negative way. High-quality multicultural literature has indeed been previously described as showing cultural authenticity at the character-level in terms of actions, thoughts, emotions or language use (e.g., AlHazza and Bucher 2008; Salas et al. 2002).

\section{Analyzing the story}

Cultural authenticity at the story-level can be found in values, traditions, aspects of history and beliefs that are described (e.g., Al-Hazza and Bucher 2008; Salas et al. 2002). Apart from cultural authenticity, CRT and CMA call for an analysis of perspectives and ideologies that predominate. Ideologies that are particularly relevant in relation to ethnicity and culture are ideologies favoring White people (White supremacy) or Western cultures (eurocentrism). In addition, colorblindness and race 
neutrality have been identified as normative presuppositions in children's literature (Huber et al. 2018), implying that specific experiences of people of color related to their ethnicity tend to receive little attention in these stories.

Based on the role and importance given to ethnic and cultural details, different types of books can be distinguished. Bishop's work (Bishop 2012) formed the basis for a framework applied to general multicultural children's literature, using the categories culturally specific (or culturally authentic), culturally generic (or generically American), and culturally neutral (Adam and Barratt-Pugh 2020; Möller 2016). Culturally specific books highlight the unique experience of characters of color and include cultural details to do so, while culturally generic books also feature characters of color in important roles, but do not contain any cultural details and instead focus on universal experiences. Culturally neutral books, in addition, feature people of color, but are about a very different topic. Culturally specific books generally are high in cultural accuracy and authenticity, while culturally generic and neutral books are not (Möller 2016). Studies outside the Netherlands applying this framework earlier concluded that there is a need for more culturally specific, and thus authentic, children's books in order for children's literature to become more inclusive (Adam and Barratt-Pugh 2020).

\section{The present study}

The present study will provide a qualitative analysis of popular books for young children featuring characters of color in the Netherlands through the combined lens of CRT and CMA. Results from the present study will provide an insight in the messages concerning diversity and the portrayal of various cultures in books that young children in the Netherlands are likely to be exposed to. These insights will in addition be informative in terms of the types of multicultural children's books that are represented. Results can lead to suggestions for authors, illustrators, publishers and consumers regarding room for improvement in terms of cultural specificity and authenticity in books, as well as underlying power relations that predominate children's books.

\section{Method}

\section{Materials and procedure}

The book selection process consisted of several steps (see Fig. 1). We selected books that had been (1) sold most, (2) borrowed most, or (3) received an award from 2009 until 2018 in the Netherlands, based on information from the CPNB (Stichting Collectieve Propoganda van het Nederlandse Boek, a foundation aimed at the promotion of reading and book ownership) and various awards (Prentenboek van het jaar, Kinderboekwinkelprijs, Wouter Pieterse prijs, Griffels en Penselen, IBBY Honour List, Boekensleutel, Hotze de Roos Prijs, Jenny Smelik-IBBY-Prijs and Prijs van de 


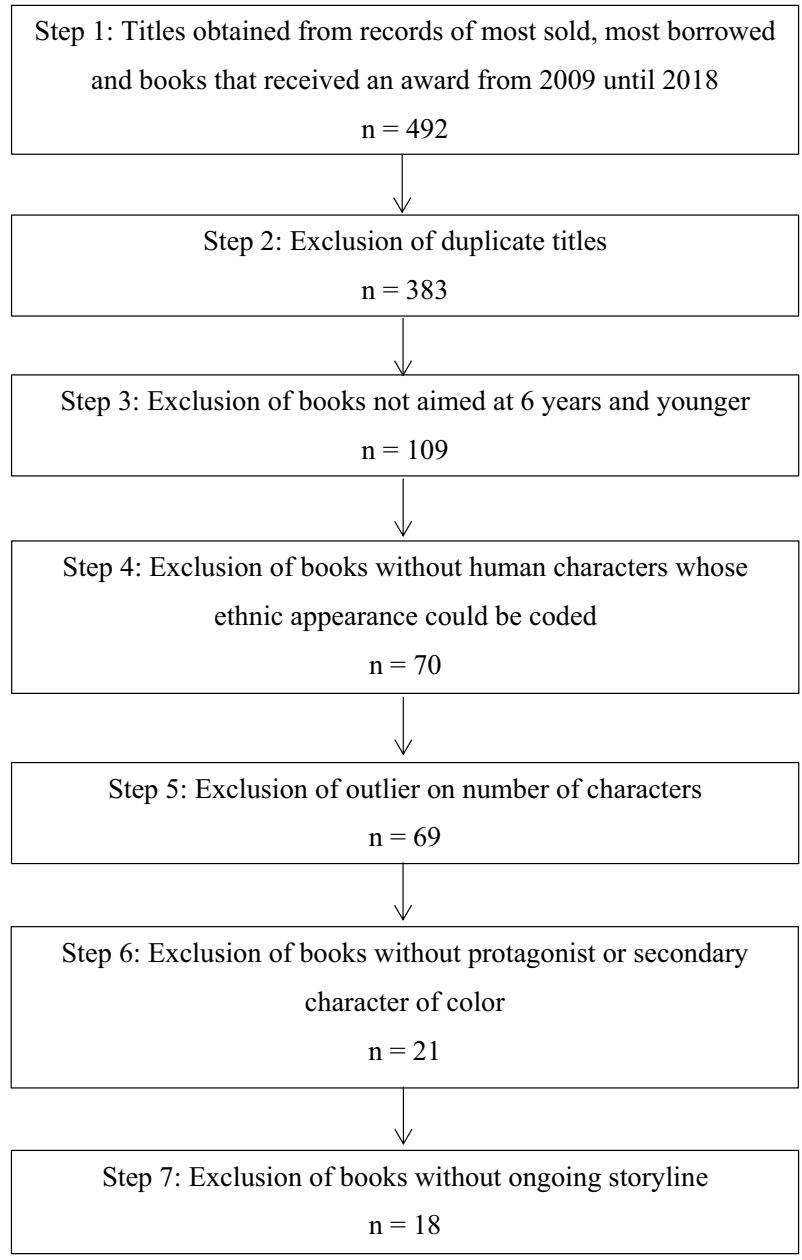

Fig. 1 Process of book selection

Kinderjury). Duplicates, books not aimed at children of six years old and younger (as indicated by the majority of libraries in three large cities in the Netherlands: Amsterdam, Rotterdam and The Hague), and books without human figures whose ethnic appearance could be coded were excluded. In addition, one outlier regarding the number of human characters (estimated at 3343) was excluded. ${ }^{1}$ The remaining books were firstly coded quantitatively (for the complete quantitative coding process, see de Bruijn et al. 2021), after which the selection process for the qualitative analysis continued.

\footnotetext{
${ }^{1}$ Nederland by Charlotte Demantons was excluded because the book contained an extreme number of characters that would skew the quantitative analysis. Furthermore, as there was no story line, rather the book consists of separate scenes, the book could not be analyzed qualitatively.
} 
Of the 69 remaining books, 21 books included a protagonist or secondary character of color, which was defined as a character with an ethnic appearance that was not White, European/Caucasian, based on physical characteristics such as skin color, hair structure, and cultural aspects such as traditional clothing. Books without any characters of color $(n=37)$ or with only background characters of color $(n=11)$ were not included for the qualitative analysis, because these books would not include enough detail about characters of color to serve the purpose of the study. In addition, three books that did not contain one storyline throughout the book but were made up of either short poems $(n=2)$, or only pictures and single words $(n=1)$ were excluded. The remaining 18 titles, of which two were translated from English and others were in Dutch originally (see Online Appendix A for the full list), were selected to be read multiple times and analyzed qualitatively, while focusing on both images and text to capture all the information presented and applying both CRT and CMA. It should be noted that five of the remaining titles were part of the same series, and thus partly featured the same characters (books number 13 to 17, Online Appendix A).

During each reading, observations in the following categories were noted: cultural specificity, cultural authenticity, power relations. These categories were derived from example questions on how to apply CRT and CMA by Huber et al. (2018) and by Botelho and Rudman (2009). The example questions were interpreted as implying a necessary focus on the ways in which the story 'becomes raced' (cultural specificity), the identities and characteristics assigned to people of color (cultural authenticity), dominant ideologies, other power operations, and social processes among characters (power relations; Huber et al. 2018; Botelho and Rudman 2009). Observations for the category cultural specificity were guided by the following questions: (1) Is the cultural background of the character of color mentioned or specified, and if so, to what purpose (i.e., how does it play a role in the story)? (2) How specific is the ethnic appearance of the character of color (i.e., is there only a difference in skin color or are other ethnicity related features used)? (3) Are any ethnicity-related features mentioned in the text and if so, to what purpose? Cultural authenticity was examined by assessing the degree of stereotypes and culturally accurate details portrayed in (1) character behaviors, emotions, and descriptions (i.e., are these positive or negative and are they stereotypical?), (2) settings in which characters are portrayed, and (3) values that are transmitted through character actions. Positive and negative descriptions are based on adjectives used to describe characters, inspired by (but not limited to) distinctions between positive and negative adjectives as used in child attitude measures (e.g., Preschool Racial Attitude Measure, Williams et al. 1975). Stereotypes were conceptualized as characteristics, behaviors, descriptions, or attributes with negative connotations or othering effects, often or typically associated with an ethnic group, distinguishing them from other ethnic groups. However, we acknowledge that there is some tension between stereotypes and accuracy (Judd and Park 1993), which highlights that our interpretation might be different from how readers read and identify with characters. Observations in terms of power relations were guided by the following questions: (1) What relations does the character of color have with White characters? (2) How is power distributed among characters (e.g., in terms of status or active/passive behavior)? (3) 
Do dominant ideologies such as White supremacy, eurocentrism and colorblindness prevail and if so, how? Results were combined to make inferences about the types of books as defined based on work by Bishop (Adam and Barratt-Pugh 2020; Möller 2016). Given that all books featured a character of color as a protagonist or supporting character we did not expect any culturally neutral books, and results on cultural specificity and authenticity were indicative of books being culturally specific (featuring unique experiences of characters of color) or culturally generic (featuring more universal experiences without cultural details).

One third of the books was coded by three members of the research team (a White female, an Asian-European female and an Afro-Dutch male). The coding of the other books was done by one coder, a White cisgender female. Results from her observations were presented to the other authors and discussed. Specifically the distinction between accuracy and stereotypes posed some initial difficulties that were discussed among the authors to reach consensus. The research team is ethnically diverse, and the other authors are a White Dutch and Asian-European female (all cisgender). The team has extensive experience with research among different ethnic groups on interethnic attitudes, stereotypes, and prejudice of parents and children, as well as with service to public organizations through advice on intercultural issues.

\section{Results}

\section{Cultural specificity}

In five of the 18 books, explicit references were made to the cultural background or nationality of characters of color. In these stories, the reference is used to describe (1) an adoption process (Baby'tje in mama's buik, Vriendjes van overal), (2) migration and homesickness (Bij ons in de straat, Dit is voor jou, Jan Toorop-Lied van de tijd), and (3) aid to countries in the Global South (Vriendjes van overal). In three of these cases, the cultural background or country of origin was not named specifically but descriptions as 'from far' or 'the country of parrots' were used (Baby'tje in mama's buik, Bij ons in de straat, Dit is voor jou). In the other two books, a specific heritage was mentioned in the context of the current country of residence (Jan Toorop-Lied van de tijd, Vriendjes van overal).

In four of the 18 books, indirect descriptions in combination with appearances help understand the specific cultural background of the characters of color. These descriptions included languages characters speak or clothing (i.e., being able to speak Arabic and wearing a hijab; Vriendjes van overal), characters' food preferences (i.e., couscous; Slagroom op je snoet), specific language use (i.e., 'dushi', a word from Papiamento; Naar opa en oma pannenkoek), and the setting surrounding characters (i.e., living in a palace in Islamic architectural style; Beste Bregje Boentjes). Although the last description was clearly used to create an unfamiliar, but exotic and adventurous setting, the other descriptions did not serve such a clear purpose in the story and were used in settings very familiar to young children: in the classroom and while visiting family. Although this was not a predefined question to guide coding, it was noticeable that responses to these implied references by White 
characters were mixed: whereas the White character in the Middle Eastern palace seemed impressed and interested (Beste Bregje Boentjes), another White character was worried when a character of color used an unfamiliar word (Naar opa en oma pannenkoek). A similar reaction tapping into fear of the unknown, and specifically fear of Africa, is found in a book in which the main character is a bit scared of the African department of the museum (Omdat ik je zo graag zie).

In the majority of the 18 books, $(n=10)$ no explicit nor implicit reference to a specific cultural background was provided, and ethnic appearance was the only indicator that characters were not White. The appearances of the characters of color were mostly culturally specific: the characters not only had a different skin tone, but also other ethnicity-related characteristics, such as facial features, hair structure, hair style and clothing. These ethnicity-related characteristics were rarely mentioned in the text, rather, it seems that most books $(n=14)$ did not include these descriptions in text. One book for example did mention several other details of a character's appearance (i.e., her dress, the flower in her hair), but did not mention skin color or hair structure (Verliefd). In four books, ethnicity-related physical characteristics are mentioned. In three of these cases, the description is very brief, as it only concerns hair color (Vriendjes van overal), or the mention of a beard (Alle dieren drijven, Held op sokken). The other exception is a more extensive discussion with a specific purpose, as it explains similarities and differences in appearance between the character of color and his (adoptive) parents (Baby'tje in mama's buik).

\section{Cultural authenticity}

\section{Character level}

Cultural authenticity can be examined at character and story level. At character level, this includes their behaviors, emotions and descriptions. Because books for young children mostly contain relatively short story lines with few words, the description of characters is often not very detailed. In none of the books the characters of color were explicitly described negatively or disliked by other characters. On the contrary, the characters were explicitly described with positive adjectives in several books (e.g., sweet, intelligent, kind, working hard, strong, Alle dieren drijven, Held op sokken, Verliefd). Because of the limited details, in half of the books descriptions of characters' behavior and emotions were neither culturally authentic nor stereotypical $(n=9)$. In two books, in the context of migration, the characters of color showed emotions and behaviors that could be described as appropriate and culturally authentic, as they are similarly identified in real-world populations. A Middle Eastern character, about whom the suggestion was aroused that he was a refugee, was described as being homesick (Bij ons in de straat), which is in line with selfreported stressors of refugees in the Netherlands (Gerritsen et al. 2006), but could at the same time reinforce the potentially stereotypical notion that migrants' main tie will be with their country of origin. A Black character, in addition, re-migrated to live with his family (Dit is voor jou), which is one of the main reasons of remigration to for example Suriname (General Bureau of Statistics 2013). In addition, an example of a counterstereotype is found in the book Handje, displaying a Black 
father and his son in the zoo, which counters the stereotype that Black fathers are absent or less involved in the caretaking of children (Thomas et al. 2008).

In contrast, the behavior of characters in some books seemed more stereotypical. A Black boy, for example, was described as very flexibly swinging in the trees, while his White female friend was very cautious and not able to do the same (Kersenhemel), which could be seen as both a gender stereotype and an ethnic stereotype linking to the dehumanization of Black people by associating them with monkeys (Goff et al. 2008), or to the stereotype of heightened athletic ability (Harrison 2001). In addition, the only classmates of color (one Moroccan and one Black) in the books from the same series (Series Jimmy and Lisa) were described as the most busy, outgoing, funny and cheeky in the classroom, which could tap into both an ethnic and gender stereotype about problematic behaviors and externalizing problem behavior. Generally, externalizing problem behaviors are reported more often for boys and children from underrepresented groups, specifically Moroccan and Surinamese, in the Netherlands, although it is unclear whether these differences reflect actual behavior differences or rater bias (Zwirs et al. 2011). However, the characters were not explicitly described as having externalizing problem behaviors. Therefore, the characters might also be perceived by children very positively and provide opportunities for children with similar behavioral patterns to identify with. There was also one example of characters of color together with White characters showing behaviors stereotyping others, as the characters in Vriendjes van overal dressed up as different nationalities in very traditional ways.

\section{Story level}

At the story level, cultural authenticity can be found in appropriate settings and values. In most of the 18 books studied $(n=13)$, characters of color were not displayed in culturally specific settings, but were found in more general settings such as at home (without cultural references), at school, in public places like a park or zoo, on the street, in the city, or in fantasy-like worlds. In one of the books, cultural decorations and festivities (i.e., with references to dragons and lanterns) accurate for Chinese culture are portrayed (Wang et al. 2014), even though cultural background did not play a significant role in the story (De tuinman van de nacht). In two books covering migration stories, thus in which cultural background did play a role, the characters of color were displayed in culturally accurate settings representing their country of origin, by displays of landscapes and forms of nature common in those countries and very different from the other settings in the book, representing the Western country (Dit is voor jou, Jan Toorop_Lied van de tijd). In another migration story, in contrast, the house of a Middle Eastern character resembling Islamic architecture was more stereotypical, as the story is situated in a Western society (Bij ons in de straat). It should be noted, however, that all other homes introduced were also very stereotypical for those characters (e.g., a sailor living in a boat and an old lady living in a knitted house). Although in another book a palace with Islamic architecture is more appropriate, as that part of the story is set in the Middle East, details such as a dressed monkey, a magic carpet and a harem of women in the 
background make the setting more stereotypical (Beste Bregje Boentjes), with some aspects reminding readers of Disney's Aladdin (Elturki and Shaman 2013).

Given the often not very detailed stories, in most of the 18 books studied no culturally authentic nor stereotypical values were identified $(n=13)$. A few examples of culturally authentic values were found. To start, two books referred to values appropriate for the Middle Eastern characters (without a reference to a specific cultural background), such as hospitality, working hard to reach achievement and the importance of family (Alle dieren drijven, Bij ons in de straat). Indeed, family solidarity and (academic) aspirations for children generally tend to be of great importance to migrants from for instance Turkey and Morocco (Merz et al. 2009; Phalet and Schönpflug 2001), and hospitality is in line with interdependent ideals common in Middle Eastern cultures (Buda and Elsayed-Elkhouly 1998). In another book, interdependent values commonly associated with Asian culture (Markus and Kitayama 1991) were portrayed through an Asian character whose main goal was to improve society, without being acknowledged for it (De tuinman van de nacht). Simultaneously, however, this could be interpreted as a serving role of this character. Lastly, in the story featuring a remigrating Black character, a degree of patriotism and love for the home country was portrayed (Dit is voor jou), which seems common in the context of remigration, as Suriname being the home country is most often named of as the reason for remigration (General Bureau of Statistics 2013). In contrast, the harem of women in the Middle Eastern palace in another book touched upon stereotypical power relations among dominant males and submissive females (Beste Bregje Boentjes).

\section{Power relations}

In most of the 18 books $(n=10)$, the characters of color had interethnic friendships with White characters (Dit is voor jou, Held op sokken, Kersenhemel, Series Jimmy and Lisa, De tuinman van de nacht, Verliefd). In four books, the characters of color had White family members with whom they had a close and positive relationship (Baby'tje in mama's buik, Heb jij misschien olifant gezien?, Naar opa en oma pannenkoek, Omdat ik je zo graag zie). In terms of power relations, the characters of color were generally portrayed as equal to the White characters in interethnic friendships. In one case, the character of color is clearly in a passive role of being someone's love interest (Verliefd), while in other $(n=7)$ cases, the characters of color were more active and dominant. Jimmy in the Series Jimmy and Lisa, for example, often took the lead and decided what to do, at the same time resembling gender stereotypical role patterns, and the characters of color in Dit is voor jou and De tuinman van de nacht taught others their skills and, implicitly, important values and life lessons. In three books, however, the power relations furthermore resembled another power structure. In one, a character of color seemed dependent on and worked on the property of a White character (Kersenhemel). In another, the character of color living abroad was rich and seemingly powerful, yet his family member living in a Western society had a low-status profession (Beste Bregje Boentjes). Furthermore, the description of the only character of color in a book introducing all residents in a 
street (i.e., as being very sad and singing songs about homesickness at night), seems intended to evoke pity while this is not the case for the White characters (Bij ons in de straat).

Although there are no explicit examples of White supremacy in the books, the three examples mentioned above do suggest that these characters of color in Western settings have a relatively low status. In addition, eurocentrism is identified in two stories in which Western countries 'help out' individuals in non-Western countries, through adoption processes or aid programs (Baby'tje in mama's buik, Vriendjes van overal). Furthermore, one example of applying Western standards is a character of color offering to adapt accordingly (i.e., abandon his harem, Beste Bregje Boentjes). One of the books in contrast seems to highlight diversity in the illustrations (showing flags from numerous countries, a lot of diversity in people, mannequins in the shop window, and types of dogs), but without explicitly mentioning it (Omdat ik je zo graag zie). Earlier, it was already established that few references to cultural background were made, that these were mostly non-specific, and that in few of the books ethnicity-related physical characteristics were mentioned in text. In combination with the lack of cultural authenticity as described above, these statistics imply a degree of colorblindness, as little attention is paid to cultural and ethnic details and experiences.

\section{Types of books}

In 7 of the books studied, no aspects of cultural specificity or authenticity were identified for the characters of color, indicating that these are culturally generic, as they do not include any cultural details or stereotypes at character or story level. In the 11 other books, there was an explicit or implicit reference to a specific cultural background, or some degree of cultural authenticity was identified.

A combination of both was found in only three books (Bij ons in de straat, Dit is voor jou, Jan Toorop-Lied van de tijd). These could be categorized as culturally specific, although the degree of cultural specificity is limited to descriptions of a 'different' (but no specific) background in two of these books (Bij ons in de straat, Dit is voor jou), some degree of stereotypes is also identified in one of the books (Bij ons in de straat), and only one of these books showed aspects of cultural authenticity on both the character and story level (Dit is voor jou). Therefore, even within books categorized as culturally specific, there is room for more cultural specificity and authenticity to fully meet the description of highlighting the unique experience of characters of color and including cultural details to do so. The other books in which some degree of cultural specificity or cultural authenticity was found $(n=8)$ can be divided into two groups: in five of these books, explicit or implicit references to cultural backgrounds were made but no other cultural details or authentic aspects were included or stereotypes were shown, while in the other three no references to cultural backgrounds were made, but culturally authentic values in accordance with the ethnic appearance of characters were portrayed in the story. These eight books fall somewhere in between the categories culturally generic and culturally specific, as they do not contain no cultural details at all (culturally generic), but also do not 
use enough cultural details to highlight the unique experience of characters of color (culturally specific).

\section{Discussion}

In this study, popular children's books in the Netherlands that featured characters of color as protagonists or secondary characters were analyzed through the lens of CRT and CMA, to examine messages about various cultures and characters of color that are conveyed to young children. Combining information on cultural specificity and authenticity revealed that only three out of 18 books could cautiously (as there was still room for more specificity and authenticity) be categorized as culturally specific. Other books included less or no cultural specificity or authenticity, and some (implicit) examples of prevailing ideologies including colorblindness, white supremacy and eurocentrism were identified.

In terms of cultural specificity, findings showed that in only a few books, an explicit reference to the cultural or ethnic background of a character of color was made. These references were not always specific but for instance referred to 'being from far away'. These descriptions imply that although the fact that the character was 'from elsewhere', and thus different from the other characters, was important to mention, the specific cultural background did not matter. Therefore, the degree of cultural specificity is debatable and descriptions could reflect a form of othering. The explicit references were only made in very specific situations, namely in stories about adoption, migration or development aid. This could convey the message that explicitly talking about cultural backgrounds should only happen in very specific situations that explicitly concern differences between people or countries. In contrast, most implicit references to cultural or ethnic backgrounds did not serve a clear purpose in the story and were used in stories about the daily lives of children, such as talking about language knowledge at school. On the one hand, these examples ensure that children are exposed to culturally specific details in contexts that are very familiar to them, potentially normalizing these details, but on the other hand it is unlikely that young readers can easily understand these implied references and link them to specific cultures. Although characters of color were drawn with ethnicity-related characteristics in addition to skin color, such as hair styles or in some cases clothing, most books did not refer to these characteristics in text. These results imply that most stories did not 'become raced', to answer the exemplary question based on CRT (Huber et al. 2018).

Avoiding the topic of ethnicity is a key feature of the colorblind ideology that has been described as normative in children's literature (Huber et al. 2018; Winograd 2011), and is often practiced by White parents (Pahlke et al. 2012). Notably colorblindness refers to the avoidance of topics on all ethnicities, including White, although the depiction and discussion of White characters was not analyzed in the present study, in line with common applications of colorblindness in White normative settings. Although the use of group labels is thought to contribute to othering and negative intergroup attitudes (e.g., Bigler and Liben 2007), using colorblind strategies can also result in bias (e.g., Apfelbaum et al. 2010). Increasingly, scholars 
argue that silence on the topic contributes to the problem and thus encourage discussions about race and racism by parents (Perry et al. 2021) and teachers (Boutte et al. 2011). Specifically shared-book reading is thought to be a strategy to discuss concrete and observable physical aspects of diversity with young children (Kemple et al. 2016). The results from the present study, showing that references to these aspects were not often made in text, imply that the initiation of these conversations is very dependent on the adults reading the books, even more so than when textual references would create openings. Given that White parents generally seem reluctant to initiate conversations about ethnicity (Vittrup 2018), explicit discussions of this topic in children's books might help them start a conversation. These parent-child race- or ethnicity-related discussions, in contrast to colorblind parenting, could eventually help improve children's intergroup attitudes and thereby reduce bias (Vittrup and Holden 2011), although more detailed research on the content of these discussions and socialization practices is highly needed.

Apart from not mentioning ethnicity-related characteristics of appearance, the lack of details in stories in books aimed specifically at young children is an obstacle in examining cultural authenticity or stereotypes. Therefore, in the majority of books no cultural authenticity or stereotypes were found on the character or the story level. Descriptions of the characters of color were not explicitly negative (i.e., no negative adjectives were used, the characters were not disliked by other characters), on the contrary, they were either neutral (i.e., no negative or positive adjectives were used) or explicitly positive (i.e., positive adjectives such as intelligent and kind, were used). Interestingly, characters of color for whom either stereotypical or cultural authentic characteristics were found, were all male. This result highlights the importance of intersectionality (Crenshaw 1989), which emphasizes the importance of taking into account the interaction between dimensions of identity such as ethnicity and gender, and fits the first tenet of CRT that centralizes intersectionalities (Solórzano 1998). Authenticity at the story level in terms of settings and values, was found for a wide variety of cultures (Asian, Middle Eastern, Caribbean). All stereotypes found at the story level, in contrast, referred to Middle Eastern settings and values, suggesting that children are especially exposed to stereotypes pertaining to this culture. This might reinforce the relatively large perceived distance to people of Middle Eastern descent and the relatively high degree of prejudice by the White majority in the Netherlands (de Bruijn et al. 2020; Schalk-Soekar et al. 2004). Therefore, the characteristics assigned by ethnicity and the representation of people of color, to answer the exemplary questions of CRT application (Huber et al. 2018) were mostly positive but generic (i.e., without cultural details and thus accuracy). However, some examples of stereotypes specifically for males and Middle Eastern characters were found.

Nevertheless, friend or family relationships between characters of color and White characters were commonly presented in the studied books. This suggests that the books contain numerous examples of interethnic friendships, which could be conducive to the extended contact effect (Wright et al. 1997). In line with the extended contact hypothesis, the interethnic attitudes of readers could benefit from being exposed to examples of characters with an ethnic appearance similar to that of the reader being friends with characters with a different ethnic appearance. Previous 
studies have demonstrated that stories for children are capable of establishing this effect (Cameron et al. 2006, 2007). A specific focus on power within these relationships revealed that the characters of color were mostly equal to or even more dominant than the White characters in most of the books. However, some examples of power relations in line with the view of White supremacy were also identified, as were examples of eurocentrism, favoring White people and Western countries. These results tap into exemplary questions of both CRT and CMA that highlight the need to analyze ideologies and how they operate (Botelho and Rudman 2009; Huber et al. 2018). Despite the fact that not all examples were very pronounced, these ideologies can impact children's worldviews, as Sutherland (1985, p. 11) argues that 'if ideologies have potential powers of persuasion, they are no less persuasive because they are hidden'.

Although the present study investigated only a subset of books available to young children in the Netherlands, the set reflects the most popular books, as books sold most often and borrowed from libraries most often were combined with award-winning books. As the selected subset is based on records from 2009 to 2018, it would be interesting to examine books from more recent and future records to establish patterns over time. Unfortunately, the relatively small sample in the present study, and the fact that most books $(n=13)$ were included based on having won an award, precluded comparisons between categories. It is important to note that the selection process resulted in the inclusion of five books from the same series, which were the only books included based on sale ranks rather than awards (books number 13 to 17, Online Appendix A). Although this means that the same characters were represented in multiple books studied, results showed that levels of cultural specificity and authenticity among characters were different in the different books, and thus that each provides a unique perspective on messages about diversity. An important observation in the selection process was that a large proportion of books were excluded because no protagonists or secondary characters of color were represented. Additionally, the results from the present study revealed that there is a limited supply of culturally specific books that include cultural details and thereby highlight the unique experience of characters of color and often include most cultural accuracy and authenticity (Möller 2016). This result is in line with earlier studies that conclude that there is a need for more children's books that are culturally specific and authentic (e.g., Adam and Barratt-Pugh 2020).

The research team is ethnically diverse and has experience with research on the topic of interethnic attitudes and stereotypes, but it is important to note that it cannot be ruled out that their positionality and own experiences have influenced their interpretations of the materials. Although categories and accompanying questions were outlined to guide the coding process, the positionality of the research team may have played a role. We tried to diminish this risk by having one-third of the books coded by three ethnically diverse researchers, and by discussing results from all of the books with the ethnically diverse research team. However, there still is a risk that potentially descriptions that are perceived as stereotypical by others or are less familiar reflections of cultural details may have been missed in the remaining set, as most of the initial coding was done by a White scholar, and thus from a privileged perspective. Furthermore, although the questions guiding the coding 
process in the present study were based on CRT and CMA, other interpretations derived from both frameworks could not easily be applied to the books in the present study, and deserve attention in future research. For example, the historical and political contexts (CRT, Huber et al. 2018) were not included in the present study as the focus was on books for very young children with relatively short and simple, respectively, storylines. Studies zooming in on fewer books in even more detail and on books aimed at (slightly) older children could include these aspects of the theoretical frameworks as well, adding to the present results. Moreover, in addition to the content of the books, the way in which adults discuss the books with children is of great importance (see Farago et al. 2015). Future research should examine how books are read to children by parents of different ethnic backgrounds to truly examine the explicit and implicit messages that children receive during shared book reading, for example using observational studies guided by the ethnic-racial socialization framework (Hughes et al. 2006). In addition, it would be interesting to examine books focusing on the topic of diversity specifically, to see what ideologies are presented there.

The present study gives insights in the messages that are conveyed in books including characters of color aimed at young children in the Netherlands. The results highlight that the inclusion of characters of color in children's literature still deserves attention, and that this should not be focused on mere representation, but also the portrayal of enough cultural specificity and authenticity to reflect the experiences of characters of color. Only in this way can children's books reach their full potential as mirrors, windows, and glass sliding doors (Bishop 1990), and can different viewpoints and ideologies challenge the dominant ones.

Supplementary Information The online version contains supplementary material available at https://doi. org/10.1007/s43545-021-00221-7.

Author contributions All authors contributed to the study conception and design. Data collection and analysis were performed by YB. The first draft of the manuscript was written by YB. RE and JM commented on previous versions of the manuscript. All authors read and approved the final manuscript.

Funding This research did not receive any specific grant from funding agencies in the public, commercial, or not-for-profit sectors.

Data availability Materials consist of openly available sources.

\section{Declarations}

Conflict of interest There are no conflicts of interest.

Open Access This article is licensed under a Creative Commons Attribution 4.0 International License, which permits use, sharing, adaptation, distribution and reproduction in any medium or format, as long as you give appropriate credit to the original author(s) and the source, provide a link to the Creative Commons licence, and indicate if changes were made. The images or other third party material in this article are included in the article's Creative Commons licence, unless indicated otherwise in a credit line to the material. If material is not included in the article's Creative Commons licence and your intended use is not permitted by statutory regulation or exceeds the permitted use, you will need to obtain permission directly from the copyright holder. To view a copy of this licence, visit http://creativecommons.org/licen ses/by/4.0/. 


\section{References}

Adam H, Barratt-Pugh C (2020) The challenge of monoculturalism: what books are educators sharing with children and what messages do they send? Aust Educ Res. https://doi.org/10.1007/ s13384-019-00375-7

Al-Hazza TC, Bucher KT (2008) Building Arab Americans' cultural identity and acceptance with children's literature. Read Teach 62(3):210-219. https://doi.org/10.1598/RT.62.3.3

Apfelbaum EP, Pauker K, Sommers SR, Ambady N (2010) In blind pursuit of racial equality? Psychol Sci 21(11):1587-1592. https://doi.org/10.1177/0956797610384741

Becker M, McElvany N, Kortenbruck M (2010) Intrinsic and extrinsic reading motivation as predictors of reading literacy: a longitudinal study. J Educ Psychol 102:773-785. https://doi.org/10.1037/a0020 084

Berreman GD (1972) Race, caste, and other invidious distinctions in social stratification. Race 13(4):385414. https://doi.org/10.1177/030639687201300401

Bigler RS, Liben LS (2007) Developmental intergroup theory: explaining and reducing children's social stereotyping and prejudice. Curr Dir Psychol Sci 16(3):162-166. https://doi.org/10.1111/j.14678721.2007.00496.x

Bishop RS (1990) Mirrors, windows, and sliding glass doors. Perspect Choosing Using Books Classroom 6(3):ix-xi

Bishop RS (2012) Reflections on the development of African American children's literature. J Childrens Lit 38(2):5-13

Botelho MJ, Rudman MK (2009) Critical multicultural analysis of children's literature. Routledge, New York

Boutte GS, Lopez-Robertson J, Powers-Costello E (2011) Moving beyond colorblindness in early childhood classrooms. Early Childhood Educ J 39(5):335-342. https://doi.org/10.1007/ s10643-011-0457-x

Brooks W (2009) An author as a counter-storyteller: Applying critical race theory to a Coretta Scott King Award book. Child Lit Educ 40(1):33-45. https://doi.org/10.1007/s10583-008-9065-9

Brown GK, Langer A (2010) Conceptualizing and measuring ethnicity. Oxf Dev Stud 38(4):411-436. https://doi.org/10.1080/13600818.2010.525629

Buda R, Elsayed-Elkhouly SM (1998) Cultural differences between Arabs and Americans: Individualismcollectivism revisited. J Cross Cult Psychol 29(3):487-492. https://doi.org/10.1177/0022022198 293006

Cameron L, Rutland A, Brown R, Douche R (2006) Changing children's intergroup attitudes toward refugees: Testing different models of extended contact. Child Dev 77(5):1208-1219. https://doi.org/10. 1111/j.1467-8624.2006.00929.x

Cameron L, Rutland A, Brown R (2007) Promoting children's positive intergroup attitudes towards stigmatized groups: extended contact and multiple classification skills training. Int J Behav Dev 31(5):454-466. https://doi.org/10.1177/0165025407081474

Cole EM, Valentine DP (2000) Multiethnic children portrayed in children's picture books. Child Adolesc Soc Work J 17(4):305-317. https://doi.org/10.1023/A:1007550124043

Crenshaw K (1989) Demarginalizing the intersection of race and sex: a Black feminist critique of antidiscrimination doctrine, feminist theory, and antiracist politics. Univ Chicago Legal Forum 1989(1):139-167

Crenshaw KW (2010) Twenty years of critical race theory: looking back to move forward. Conn Law Rev 43(5):1253-1354

de Bruijn Y, Amoureus C, Emmen RAG, Mesman J (2020) Interethnic prejudice against Muslims among White Dutch children. J Cross Cult Psychol 51(3-4):203-221. https://doi.org/10.1177/0022022120 908346

de Bruijn Y, Emmen RA, Mesman J (2021) Ethnic diversity in children's books in the Netherlands. Early Childhood Educ J 49:413-423. https://doi.org/10.1007/s10643-020-01080-2

Elturki E, Shaman S (2013) Aladdin's wonderful lamp: how are foreign folktales conveyed in Western children's literature? Arab World English J 1:115-133

Farago F, Sanders K, Gaias L (2015) Addressing race and racism in early childhood: challenges and opportunities. Adv Early Educ Child Care 19:29-66. https://doi.org/10.1108/S0270-4021201500 00019004 
Fox DL, Short KG (2003) Stories matter: the complexity of cultural authenticity in children's literature. National Council of Teachers of English, Urbana

Frye B, Button L, Kelly C, Button G (2010) Preservice teachers' self-perceptions and attitudes toward culturally responsive teaching. J Praxis Multicult Educ 5(1):6-22. https://doi.org/10.9741/21612978.1029

General Bureau of Statistics (2013) Resultaten 8ste volkstelling in Suriname (vol 1): Demografische en sociale karakteristieken en migratie. Algemeen Bureau voor de Statistiek Suriname (GBS), Paramaribo

Gerritsen AA, Bramsen I, Devillé W, van Willigen LH, Hovens JE, Van Der Ploeg HM (2006) Physical and mental health of Afghan, Iranian and Somali asylum seekers and refugees living in the Netherlands. Soc Psychiatry Psychiatr Epidemiol 41(1):18-26. https://doi.org/10.1007/s00127-005-0003-5

Goff PA, Eberhardt JL, Williams MJ, Jackson MC (2008) Not yet human: Implicit knowledge, historical dehumanization, and contemporary consequences. J Pers Soc Psychol 94(2):292-306. https://doi.org/ 10.1037/0022-3514.94.2.292

Harrison L (2001) Understanding the influence of stereotypes: implications for the African American in sport and physical activity. Quest 53(1):97-114. https://doi.org/10.1080/00336297.2001.10491732

Huber LP, Gonzalez LC, Solórzano DG (2018) Considerations for using critical race theory and critical content analysis: a research note. Underst Dismantling Privilege 8(2):8-26

Hughes D, Rodriguez J, Smith EP, Johnson DJ, Stevenson HC, Spicer P (2006) Parents' ethnic-racial socialization practices: a review of research and directions for future study. Dev Psychol 42(5):747-770. https://doi.org/10.1037/0012-1649.42.5.747

Hughes-Hassell S, Barkley HA, Koehler E (2009) Promoting equity in children's literacy instruction: using a Critical Race Theory framework to examine transitional books. Sch Library Media Res 12:1-20

Iwai Y (2013) Multicultural children's literature and teacher candidates' awareness and attitudes toward cultural diversity. Int Electron J Element Educ 5(2):185-198

Johnson H, Gasiewicz B (2016) Examining displaced youth and immigrant status through critical multicultural analysis. In: Johnson H, Mathis J, Short KG (eds) Critical content analysis of children's and young adult literature. Routledge, New York, pp 38-53

Johnson NJ, Koss MD, Martinez M (2018) Through the sliding glass door: \#EmpowerTheReader. Read Teach 71(5):569-577

Judd CM, Park B (1993) Definition and assessment of accuracy in social stereotypes. Psychol Rev 100(1):109-128. https://doi.org/10.1037/0033-295X.100.1.109

Keita SOY, Kittles RA, Royal CD, Bonney GE, Furbert-Harris P, Dunston GM, Rotimi CN (2004) Conceptualizing human variation. Nat Genet 36(11):S17-S20. https://doi.org/10.1038/ng1455

Kelley JE (2008) Power relationships in Rumpelstiltskin: a textual comparison of a traditional and a reconstructed fairy tale. Child Lit Educ 39(1):31-41. https://doi.org/10.1007/s10583-006-9039-8

Kemple KM, Lee IR, Harris M (2016) Young children's curiosity about physical differences associated with race: shared reading to encourage conversation. Early Childhood Educ J 44(2):97-105. https://doi.org/ 10.1007/s10643-014-0683-0

Koss MD (2015) Diversity in contemporary picturebooks: a content analysis. J Childrens Lit 41(1):32-42

Koss MD, Martinez MG, Johnson NJ (2017) Where are the Latinx? Diversity in Caldecott Winner and Honor Books. Biling Rev 33(5):50-62

Malcolm ZT, Lowery RM (2011) Reflections of the Caribbean in children's picture books: a critical multicultural analysis. Multicult Educ 19(1):46-50

Markus HR, Kitayama S (1991) Culture and the self: Implications for cognition, emotion, and motivation. Psychol Rev 98(2):224-253. https://doi.org/10.1037/0033-295X.98.2.224

McNair JC (2008a) The representation of authors and illustrators of color in school-based book clubs. Lang Arts 85(3):193-201

McNair JC (2008b) A comparative analysis of The Brownies' Book and contemporary African American children's literature written by Patricia C. McKissack. In: Brooks W, McNair J (eds) Embracing, evaluating, and examining African American children's and young adult literature. Scarecrow, Lanham, pp 3-29

Merz EM, Özeke-Kocabas E, Oort FJ, Schuengel C (2009) Intergenerational family solidarity: value differences between immigrant groups and generations. J Fam Psychol 23(3):291-300. https://doi.org/10. 1037/a0015819

Milner HR IV (2008) Critical race theory and interest convergence as analytic tools in teacher education policies and practices. J Teach Educ 59(4):332-346. https://doi.org/10.1177/0022487108321884 
Möller KJ (2016) Creating diverse classroom literature collections using Rudine Sims Bishop's conceptual metaphors and analytical frameworks as guides. J Childrens Lit 42(2):64-74

Nikolajeva M, Scott C (2013) How picturebooks work. Routledge, New York

Pahlke E, Bigler RS, Suizzo M (2012) Relations between colorblind socialization and children's racial bias: evidence from European American mothers and their preschool children. Child Dev 83(4):1164-1179. https://doi.org/10.3138/jcfs.32.4.489

Pauker K, Williams A, Steele JR (2017) The development of racial categorization in childhood. In: Rutland A, Nesdale D, Brown CS (eds) The Wiley handbook of group processes in children and adolescents. Wiley-Blackwell, Hoboken, pp 221-239. https://doi.org/10.1002/9781118773123.ch11

Perry S, Skinner-Dorkenoo A, Abaied JL, Waters S (2021) Applying what evidence we have: support for having race conversations in White U.S. families. PsyArXiv. https://doi.org/10.31234/osf.io/8dpru

Phalet K, Schönpflug U (2001) Intergenerational transmission in Turkish immigrant families: parental collectivism, achievement values and gender differences. J Comp Fam Stud 32(4):489-504

Quintana SM (1994) A model of ethnic perspective-taking ability applied to Mexican-American children and youth. Int J Intercult Relat 18(4):419-448. https://doi.org/10.1016/0147-1767(94)90016-7

Quintana SM (1998) Children's developmental understanding of ethnicity and race. Appl Prev Psychol 7(1):27-45. https://doi.org/10.1016/S0962-1849(98)80020-6

Richards WS (2013) Jamaican children's literature: a critical multicultural analysis of text and illustration in Jamaican picturebooks for children published between 1997-2012. Doctoral dissertation. https://conse rvancy.umn.edu/bitstream/handle/11299/165773/Richards_umn_0130E_14094.pdf?sequence=1\&isAll owed $=\mathrm{y}$

Roethler J (1998) Reading in color: children's book illustrations and identity formation for Black children in the United States. Afr Am Rev 32(1):95-105. https://doi.org/10.2307/3042272

Salas RG, Lucido F, Canales J (2002) Multicultural literature: broadening young children's experiences. In: Cassidy J, Garret S (eds) Early Childhood Literacy: programs and strategies to develop cultural, linguistic, scientific and healthcare literacy for very young children and their families. Centre for Educational Development, Evaluation, \& Research, Texas A\&M University, Corpus Christi, pp 139-150

Schalk-Soekar SR, van de Vijver FJ, Hoogsteder M (2004) Attitudes toward multiculturalism of immigrants and majority members in the Netherlands. Int J Intercult Relat 28(6):533-550. https://doi.org/10.1016/j. ijintrel.2007.11.001

So JK (2016) Opening up spaces for early critical literacy: Korean kindergarteners exploring diversity through multicultural picture books. Aust J Lang Lit 39(2):176-187

Solórzano DG (1997) Images and words that wound: critical race theory, racial stereotyping, and teacher education. Teach Educ Q 24:5-19

Solórzano DG (1998) Critical race theory, race and gender microaggressions, and the experiences of Chicana and Chicano scholars. Qual Stud Educ 11(1):121-136. https://doi.org/10.1080/095183998236926

Sutherland RD (1985) Hidden persuaders: Political ideologies in literature for children. Child Lit Educ 16(3):143-157

Thomas PA, Krampe EM, Newton RR (2008) Father presence, family structure, and feelings of closeness to the father among adult African American children. J Black Stud 38(4):529-546. https://doi.org/10. $1177 / 0021934705286101$

Vittrup B (2018) Color blind or color conscious? White American mothers' approaches to racial socialization. J Fam Issues 39(3):668-692. https://doi.org/10.1177/0192513X16676858

Vittrup B, Holden GW (2011) Exploring the impact of educational television and parent-child discussions on children's racial attitudes. Anal Soc Issues Public Policy 11(1):82-104. https://doi.org/10.1111/j. 1530-2415.2010.01223.X

Wang J, Tang X, Pang Y, Duan W (2014) Analysis on modern anomie situation of Chinese traditional festivals. Asian Culture Hist 6(2):56-63. https://doi.org/10.5539/ach.v6n2p56

Williams JE, Best DL, Boswell DA, Mattson LA, Graves DJ (1975) Preschool racial attitude measure II. Educ Psychol Measur 35(1):3-18

Winograd K (2011) Sports biographies of African American football players: the racism of colorblindness in children's literature. Race Ethn Educ 14(3):331-349. https://doi.org/10.1080/13613324.2010.519983

Wright SC, Aron A, McLaughlin-Volpe T, Ropp SA (1997) The extended contact effect: knowledge of crossgroup friendships and prejudice. J Pers Soc Psychol 73(1):73-90. https://doi.org/10.1037/0022-3514. 73.1 .73

Yoo-Lee E, Fowler L, Adkins D, Kim KS, Davis HN (2014) Evaluating cultural authenticity in multicultural picture books: a collaborative analysis for diversity education. Libr Q 84(3):324-347. https://doi.org/10. 1086/676490

\section{SN Social Sciences}


Zwirs B, Burger H, Schulpen T, Vermulst AA, HiraSing RA, Buitelaar J (2011) Teacher ratings of children's behavior problems and functional impairment across gender and ethnicity: construct equivalence of the Strengths and Difficulties Questionnaire. J Cross Cult Psychol 42(3):466-481. https://doi.org/10.1177/ 0022022110362752 